\title{
Use of Bisphosphonates in Elderly Patients With Newly Diagnosed Multiple Myeloma
}

\author{
Siyang Leng, MD, MSa; Yizhen Chen, MS; Wei-Yann Tsai, $\mathrm{PhD}^{\mathrm{b}}$; Divaya Bhutani, MDa; \\ Grace C. Hillyer, EdD, MPH ${ }^{c, d}$; Emerson Lim, MD, MS ${ }^{a, c}$; Melissa K. Accordino, MD, MSa,c; \\ Jason D. Wright, MD, MS d,e; Dawn L. Hershman, MD, MS ${ }^{a, c, d}$; \\ Suzanne Lentzsch, MD, PhD ${ }^{a, c_{,}{ }^{*}}$; and Alfred I. Neugut, MD, PhD ${ }^{a, c, d,{ }^{*}}$
}

\begin{abstract}
Background: Bisphosphonates reduce skeletal-related events (SREs) in patients with multiple myeloma (MM) and, in some studies, improved survival. Since 2011, bisphosphonate use has been recommended by NCCN for all patients with newly diagnosed MM receiving antineoplastic therapy independent of the presence of bone disease. This study investigated their use after these guidelines were established. Methods: We identified patients aged $\geq 65$ years in the SEER-Medicare database with newly diagnosed MM between January 1, 2012, and December 31, 2013, who received antineoplastic therapy, had $\geq 6$ months of follow-up, and did not receive prior bisphosphonates. Presence of SREs at diagnosis was identified, including pathologic fracture, spinal cord compression, radiation to bone, or surgery to bone. Use of bisphosphonates was defined as having $\geq 1$ claim for an intravenous or oral bisphosphonate within 6 months after the start of antineoplastic therapy. We used multivariable modeling to compare users with nonusers, controlling for demographic and clinical covariates. We compared overall survival between users and nonusers using proportional hazards analysis. Results: Of 1,309 patients identified, 720 (55\%) used a bisphosphonate. Factors associated with use included SRE at diagnosis (adjusted odds ratio [AOR], 2.60; 95\% Cl, 1.98-3.40), hypercalcemia (AOR, 1.74; 95\% Cl, 1.26-2.41), and use of proteasome inhibitor + immunomodulatory imide therapy (AOR, 1.70; 95\% Cl, 1.21-2.39). Chronic kidney disease ( $A O R, 0.48 ; 95 \% \mathrm{Cl}, 0.35-0.66$ ) was associated with decreased use. Bisphosphonate use was associated with reduced mortality (hazard ratio, $0.70 ; 95 \% \mathrm{Cl}, 0.56-0.88$ ). Conclusions: Although bisphosphonate use is recommended for all patients with newly diagnosed MM receiving antineoplastic therapy, $45 \%$ of patients in the United States did not receive this guideline-recommended care.
\end{abstract}

J Natl Compr Canc Netw 2019;17(1):22-28 doi: 10.6004/jnccn.2018.7079

\footnotetext{
aDepartment of Medicine, Columbia University College of Physicians and Surgeons; 'b Department of Biostatistics, Columbia University Mailman School of Public Health; 'Herbert Irving Comprehensive Cancer Center, Columbia University College of Physicians and Surgeons; ${ }^{d}$ Department of Epidemiology, Columbia University Mailman School of Public Health; and eDepartment of Obstetrics and Gynecology, Columbia University College of Physicians and Surgeons, New York, New York.

${ }^{*}$ Contributed equally as senior authors.
}

Multiple myeloma (MM) is a hematologic malignancy characterized by significant bone disease; lytic lesions are present in $>60 \%$ of patients at diagnosis, as are pathologic fractures, osteoporosis, and hypercalcemia. ${ }^{1}$ Due to the frequency and morbidity of bone disease in these patients, guidelines from NCCN, ASCO, International Myeloma Working Group, and European Myeloma Network all recommend use of the bisphosphonates zoledronic acid and pamidronate in patients receiving primary $\mathrm{MM}$ therapy. ${ }^{2,3}$ In 2018, NCCN and ASCO updated their recommendations to include the osteoclast inhibitor denosumab as an alternative antiresorptive agent, based on evidence showing that it is noninferior to zoledronic acid in delaying time to first skeletal-related event (SRE).,5

Considerable evidence from randomized controlled trials supports the use of bisphosphonates. Pamidronate and zoledronic acid have been shown to significantly reduce SREs (defined as pathologic fracture, radiation to bone, surgery on bone, and spinal cord compression) and bone pain, with some studies showing a relative risk reduction of $16 \%$ to $17 \%$, 6 and another showing an absolute risk reduction of 0.9 SREs per year. ${ }^{8}$ Whether bisphosphonates improve survival is controversial and may vary based on the specific agent used. ${ }^{9}$ Pamidronate was associated with a survival benefit in one study of patients with relapsed or refractory MM (median, 21 months survival in users vs 14 in those receiving placebo; $P=.04$ ). ${ }^{8}$ The MRC Myeloma IX trial of 1,960 patients with newly diagnosed MM found that zoledronic acid improved survival compared with clodronate, but only in those with bone disease or an SRE at baseline (hazard ratio [HR], 0.82; 95\% CI, 0.70-0.95). ${ }^{10,11}$

Compelling evidence for the benefit of bisphosphonates resulted in an update of the NCCN Clinical Practice Guidelines in Oncology (NCCN Guidelines) in 2011 to recommend bisphosphonate treatment for all patients with newly diagnosed MM receiving primary MM therapy, without contraindication. ${ }^{12}$ We performed a population-based analysis to investigate whether patients aged

See JNCCN.org for supplemental online content. 
$\geq 65$ years received bisphosphonates in accordance with the guidelines. We examined predictors for bisphosphonate use and whether use is associated with a change in survival on a population level.

\section{Methods}

\section{Data Source}

This retrospective cohort study used data from the SEER-Medicare database..$^{13}$ SEER is a population-based tumor registry developed by the NCI that captures time of diagnosis, tumor details, and sociodemographic characteristics for individuals with cancer in 18 geographic areas of the United States, representing approximately $28 \%$ of the population. ${ }^{14}$ Medicare captures billed claims submitted through inpatient (Part A), outpatient (Part B), and prescription drug (Part D) coverages. The SEER and Medicare files are linked to provide data about individual patients from time of cancer diagnosis onward. ${ }^{15}$

\section{Cohort Selection}

Individuals aged $\geq 65$ years diagnosed with MM (SEER site recode 34000) from 2012 through 2013 were included in this analysis. Patients were required to have received antineoplastic therapy appropriate for MM (supplemental eAppendix 1, available with this article at JNCCN.org) within 6 months after diagnosis and to have complete Medicare Parts A and B coverage from 12 months before diagnosis onward. We excluded patients who received bisphosphonates before MM diagnosis, had $<6$ months of follow-up after diagnosis, or were diagnosed by autopsy.

\section{Patient Characteristics}

Age at diagnosis was stratified into 65 to 74,75 to 84 , and $\geq 85$ years; race was recorded as white, black, and other; marital status was recorded as married and unmarried; and socioeconomic status was calculated from education, poverty level, and income data from the 2000 census using reported methods. ${ }^{16}$

Patients were considered to have an SRE at diagnosis if they had a claim for one within 90 days before MM diagnosis and 60 days after. An SRE was defined as pathologic fracture, spinal cord compression, radiation to bone, or surgery on bone. ${ }^{7,8,17}$ Codes used to identify SREs are listed in supplemental eAppendix 2. ${ }^{17-20}$

Presence of several comorbid conditions at any time before diagnosis of MM was recorded, including acute kidney injury, chronic kidney disease, use of hemodialysis, osteoporosis, osteopenia, and hypercalcemia. Comorbidity score was assessed using the Klabunde adaptation of the Charlson comorbidity index. ${ }^{21}$ The initial antineoplastic regimen used after diagnosis, defined as all antineoplastic drugs received within the first 90 days of treatment, was recorded and categorized as protea- some inhibitor-based (proteasome inhibitor \pm steroids), immunomodulatory imide drug (IMiD)-based, proteasome inhibitor + IMiD, proteasome inhibitor + other cytotoxic agent, and other. Specific drugs in each class and their identifying codes are listed in supplemental eAppendix 1 . Of note, steroids come in many formulations and accompanying drug codes. We examined their use, but do not believe our methodology fully captured use, given that only $58 \%$ of the patients received steroids as part of their antineoplastic regimen, which was significantly lower than expected because steroids are nearly always given.

\section{Measures}

The primary outcome of this analysis was use of bisphosphonates, defined as whether a patient received a bisphosphonate within 6 months after start of MM therapy. All bisphosphonates evaluated for use in MM were included, with a full list provided in supplemental eAppendix 3. Duration of bisphosphonate use was determined and defined as the interval between the first and last doses. We calculated the percentage of time patients received bisphosphonates while on antineoplastic therapy, with the understanding that a patient treated according to guidelines would receive bisphosphonates $100 \%$ of the time on antineoplastic therapy.

We assessed overall survival from diagnosis as a function of bisphosphonate use. Patients were followed from MM diagnosis until death, end of enrollment in SEER-Medicare, or December 31, 2014, whichever was earliest.

\section{Statistical Analyses}

We conducted univariate and multivariable logistic regression analyses to evaluate which variables were associated with use of bisphosphonates. Proportions were compared using the chi-square test. Kaplan-Meier analysis was used to evaluate survival, with hypothesis testing conducted using the log-rank test. Cox proportional hazards models were used to adjust for the effects of covariates on both outcomes, with the proportional hazards assumption evaluated using the Wald test. ${ }^{22}$ For all models, we used $\alpha<0.05$ and 2 -sided tests of statistical significance. All analyses were conducted using SAS 9.3 (SAS Institute Inc.).

This study used deidentified data and was deemed exempt by the Columbia University Medical Center Institutional Review Board.

\section{Results}

We identified 1,309 patients between January 1, 2012, and December 31, 2013, with a diagnosis of MM, who received chemotherapy within 6 months of diagnosis, and who had $\geq 6$ months of follow-up after diagnosis (Figure 1 ). 


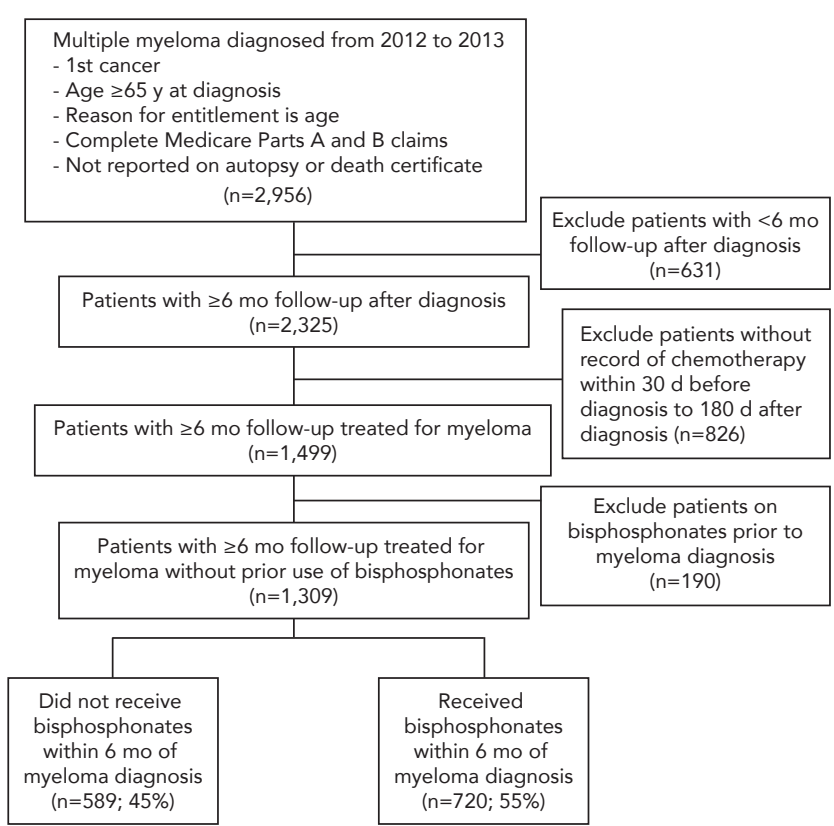

Figure 1. Cohort selection of patients aged $\geq 65$ years with newly diagnosed multiple myeloma who received antineoplastic therapy in the SEER-Medicare database, 2012-2013. Patients were evaluated for bisphosphonate use.

Among them, 720 (55\%) received at least one dose of a bisphosphonate within 6 months after the start of antineoplastic therapy, whereas 589 (45\%) did not.

Zoledronic acid was the most common bisphosphonate, used in 640 of the 720 patients (89\%). Pamidronate was used in 139 patients (19\%). A total of 84 patients (12\%) received $>1$ bisphosphonate agent over the course of their treatment, with the most common combination being zoledronic acid and pamidronate in 66 patients. Median time to initiation of bisphosphonates from MM diagnosis was 52 days (interquartile range [IQR], 26-152 days).

Among users, the median number of doses given was 8 (maximum 33; IQR, 4-13) and median duration of bisphosphonate use was 294 days (IQR, 89-569 days). On average, patients received bisphosphonates $66 \%$ (IQR, $43 \%-93 \%)$ of the time they received chemotherapy. Comparatively, patients receiving bisphosphonates every month on chemotherapy would have a coverage of $100 \%$.

Descriptive statistics for bisphosphonate users and factors associated with use are summarized in Table 1. In multivariable analysis, factors associated with decreased use of bisphosphonates were chronic kidney disease (adjusted odds ratio [OR], 0.48; 95\% CI, 0.35-0.66), hemodialysis (AOR, $0.42 ; 95 \% \mathrm{CI}, 0.24-0.75$ ), and residence in a Southern region (AOR, 0.66; 95\% CI, 0.45-0.99). Factors associated with increased use of bisphosphonates were having an SRE at diagnosis (AOR, 2.60; 95\% CI, 1.98-3.40), hypercalcemia (AOR, 1.74; 95\% CI, 1.26-2.41), and use of proteasome inhibitor +
IMiD regimens (AOR, 1.70; 95\% CI, 1.21-2.39 vs proteasome inhibitor regimens without immunomodulator).

We examined the effects of bisphosphonate use on survival using multivariable proportional hazards analysis (Table 2). Users of bisphosphonates had a lower HR for death $(0.70$; 95\% CI, 0.56-0.88) compared with nonusers after adjusting for covariates, including comorbidities and antineoplastic therapy use. Other factors associated with decreased risk of death included female sex (HR, 0.76; 95\% CI, 0.59-0.97) and proteasome inhibitor + IMiD use (HR, 0.67; 95\% CI, 0.48-0.92 when compared with proteasome inhibitor use). Factors associated with increased risk were age $\geq 85$ years (HR, 1.98 ; $95 \%$ CI, 1.37 2.87 when compared with ages $65-74$ years), hemodialysis (HR, 1.50; 95\% CI, 1.01-2.22), hypercalcemia (HR, 1.37; 95\% CI, 1.06-1.78), and higher comorbidity score (HR, 1.32 for score of $\geq 2$ vs 0 ; $95 \%$ CI, 1.01-1.72).

\section{Discussion}

This retrospective cohort study found that $55 \%$ of patients with MM diagnosed from 2012 through 2013 were started on a bisphosphonate within 6 months of initiating antineoplastic therapy. Zoledronic acid was much more frequently used than pamidronate. Although patients should be receiving bisphosphonates every month according to guidelines, on average those in our cohort received 2 doses of bisphosphonates every 3 months (66\% coverage). Having an SRE at diagnosis was a strong predictor of bisphosphonate use, as were hypercalcemia and use of proteasome inhibitor + IMiD combination regimens, whereas chronic kidney disease and hemodialysis were associated with decreased use. Use of bisphosphonates was associated with improved survival even after adjusting for demographic characteristics, comorbidities, and initial MM therapy.

Although use of bisphosphonates in MM is well supported by evidence and has been recommended by professional society guidelines for 2 decades, ${ }^{23,24}$ the real-world adoption of this practice has not been examined until recently. Investigators at Amgen Inc. examined bisphosphonate use using electronic health records from Flatiron Health, which consisted of data drawn from $>250$ cancer clinics and covering 1.5 million patients with cancer in the United States treated mostly at community practices. They found that of 11,112 patients with MM treated between 2009 and 2016, 63\% received at least one dose of pamidronate or zoledronic acid. ${ }^{25}$ Median time to bisphosphonate initiation was 29 days. Patients with chronic kidney disease were less likely to receive bisphosphonates $(72 \%$ of patients with stage 1 vs $24 \%$ with stage 5 ; HR, 0.22 ; $95 \%$ CI, 0.18-0.28).

Two other population-based analyses of bisphosphonate use in MM have been published. One study used the Veterans Affairs Central Cancer Registry to compare 


\begin{tabular}{|c|c|c|c|c|c|}
\hline & \multirow[b]{2}{*}{ Total } & \multicolumn{2}{|c|}{ Univariate } & \multicolumn{2}{|c|}{ Multivariable } \\
\hline & & n (\%) & P Value ${ }^{a}$ & AOR $^{\mathbf{a}}$ & $95 \%$ Wald $\mathrm{Cl}^{\mathrm{a}}$ \\
\hline Overall & 1,309 & 720 (55.0\%) & $\mathrm{N} / \mathrm{A}$ & $\mathrm{N} / \mathrm{A}$ & N/A \\
\hline \multicolumn{6}{|l|}{ Age, y } \\
\hline $65-74$ & 735 & 409 (55.7\%) & \multirow{3}{*}{.016} & Ref & Ref \\
\hline $75-84$ & 485 & 275 (56.7\%) & & 1.22 & $0.94-1.58$ \\
\hline$\geq 85$ & 89 & 36 (40.5\%) & & 0.66 & $0.40-1.08$ \\
\hline \multicolumn{6}{|l|}{ Sex } \\
\hline Male & 753 & 417 (55.4\%) & \multirow{2}{*}{.75} & Ref & Ref \\
\hline Female & 556 & 303 (54.5\%) & & 0.92 & $0.70-1.22$ \\
\hline \multicolumn{6}{|l|}{ Race } \\
\hline White & 1,027 & $583(56.8 \%)$ & \multirow{3}{*}{.031} & Ref & Ref \\
\hline Black & 199 & $93(46.7 \%)$ & & 0.85 & $0.59-1.21$ \\
\hline Other ${ }^{b}$ & 83 & $44(53.0 \%)$ & & 0.75 & $0.46-1.25$ \\
\hline \multicolumn{6}{|l|}{ Marital status } \\
\hline Unmarried & 543 & 293 (54.0\%) & \multirow{2}{*}{.52} & Ref & Ref \\
\hline Married & 766 & 427 (55.7\%) & & 0.92 & $0.71-1.19$ \\
\hline \multicolumn{6}{|l|}{ Region } \\
\hline North East & 219 & 125 (57.1\%) & \multirow{4}{*}{.003} & Ref & Ref \\
\hline North Central & 169 & $100(59.2 \%)$ & & 1.00 & $0.63-1.60$ \\
\hline South & 385 & $181(47.0 \%)$ & & 0.66 & $0.45-0.99$ \\
\hline West & 536 & $314(58.6 \%)$ & & 1.13 & $0.78-1.63$ \\
\hline \multicolumn{6}{|l|}{ SES rank } \\
\hline Lowest quintile & 293 & $157(53.6 \%)$ & \multirow{5}{*}{.007} & Ref & Ref \\
\hline Second quintile & 368 & $184(50.0 \%)$ & & 0.79 & $0.56-1.11$ \\
\hline Third quintile & 275 & $173(62.9 \%)$ & & 1.25 & $0.86-1.82$ \\
\hline Fourth quintile & 198 & $118(59.6 \%)$ & & 1.07 & $0.70-1.61$ \\
\hline Highest quintile & 175 & 88 (50.3\%) & & 0.73 & $0.47-1.14$ \\
\hline \multicolumn{6}{|l|}{ Acute kidney injury } \\
\hline No & 830 & $503(60.6 \%)$ & \multirow{2}{*}{$<.001$} & Ref & Ref \\
\hline Yes & 479 & $217(45.3 \%)$ & & 0.85 & $0.62-1.17$ \\
\hline
\end{tabular}

Abbreviations: AOR, adjusted odds ratio; IMiD, immunomodulatory imide agent; N/A, not applicable; Pl, proteasome inhibitor; SES, socioeconomic status; SRE, skeletal-related event.

a Statistically significant results are in bold.

${ }^{b}$ Asian, Hispanic, Native American, and unknown.

cOther cytotoxic agents \pm steroids $(n=34) ; I M i D+$ other cytotoxic agents \pm steroids $(n=10)$; and PI + IMiD + other cytotoxic agents \pm steroids $(n=26)$.

(continued on next page)

the use of zoledronic acid versus pamidronate in 1,018 newly diagnosed patients between 2002 and 2009. Patients who received zoledronic acid had significantly improved survival (HR, 0.78; 95\% CI, 0.67-0.92) and fewer SREs (HR, 0.75; 95\% CI, 0.60-0.94) compared with those treated with pamidronate. ${ }^{17}$ In comparison, our analysis found that bisphosphonates users collectively had improved survival compared with nonusers.

We did not examine the impact of bisphosphonates on SRE development due to a few concerns. Administrative claims for SREs may not accurately reflect the time of occurrence, duration, and nature of SREs, making it difficult to distinguish new SREs from existing ones. ${ }^{20}$
Additionally, our data set does not contain certain variables that reflect the degree of bone disease at diagnosis, such as results of skeletal imaging and presence of bone pain. These variables may have a significant effect on the development of SREs separate from bisphosphonate use, and we could not control for them.

A second population-based study used 2 large managed-care databases comprising commercially insured patients to compare those who received zoledronic acid versus those who did not receive any bisphosphonates. More than 1,655 patients with MM (newly diagnosed and relapsed/refractory) were identified between 2001 and 2006. Those receiving zoledronic acid had improved survival (incidence 


\begin{tabular}{|c|c|c|c|c|c|}
\hline & \multirow[b]{2}{*}{ Total } & \multicolumn{2}{|c|}{ Univariate } & \multicolumn{2}{|c|}{ Multivariable } \\
\hline & & n (\%) & $P$ Value $^{\text {a }}$ & AOR $^{\mathrm{a}}$ & $95 \%$ Wald $\mathrm{Cl}^{\mathrm{a}}$ \\
\hline \multicolumn{6}{|l|}{ Chronic kidney disease } \\
\hline No & 771 & $498(64.6 \%)$ & \multirow{2}{*}{$<.001$} & Ref & Ref \\
\hline Yes & 538 & $222(41.3 \%)$ & & 0.48 & $0.35-0.66$ \\
\hline \multicolumn{6}{|l|}{ Osteoporosis } \\
\hline No & 934 & $518(55.5 \%)$ & \multirow{2}{*}{.60} & Ref & Ref \\
\hline Yes & 375 & $202(53.9 \%)$ & & 0.76 & $0.57-1.02$ \\
\hline \multicolumn{6}{|l|}{ Osteopenia } \\
\hline No & 621 & $303(48.8 \%)$ & \multirow{2}{*}{$<.001$} & Ref & Ref \\
\hline Yes & 688 & $417(60.6 \%)$ & & 1.24 & $0.96-1.60$ \\
\hline \multicolumn{6}{|l|}{ Hypercalcemia } \\
\hline No & 1,038 & $553(53.3 \%)$ & \multirow{2}{*}{.014} & Ref & Ref \\
\hline Yes & 271 & $167(61.6 \%)$ & & 1.74 & $1.26-2.41$ \\
\hline \multicolumn{6}{|l|}{ Hemodialysis } \\
\hline No & 1,229 & $699(56.9 \%)$ & \multirow{2}{*}{$<.001$} & Ref & Ref \\
\hline Yes & 80 & $21(26.3 \%)$ & & 0.42 & $0.24-0.75$ \\
\hline \multicolumn{6}{|l|}{ Comorbidity score } \\
\hline 0 & 549 & $341(62.1 \%)$ & \multirow{3}{*}{$<.001$} & Ref & Ref \\
\hline 1 & 282 & $156(55.3 \%)$ & & 0.79 & $0.57-1.08$ \\
\hline$\geq 2$ & 462 & $217(47.0 \%)$ & & 1.05 & $0.77-1.42$ \\
\hline Missing & 16 & & & & \\
\hline \multicolumn{6}{|l|}{ Antineoplastic regimen } \\
\hline $\mathrm{PI} \pm$ steroid & 605 & $319(52.73 \%)$ & \multirow{5}{*}{.007} & Ref & Ref \\
\hline $\mathrm{IMiD} \pm$ steroid & 192 & 98 (51.04\%) & & 0.78 & $0.54-1.12$ \\
\hline 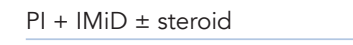 & 252 & $165(65.48 \%)$ & & 1.70 & $1.21-2.39$ \\
\hline $\mathrm{Pl}+$ other cytotoxic \pm steroid & 190 & $100(52.63 \%)$ & & 0.99 & $0.69-1.42$ \\
\hline Other ${ }^{c}$ & 70 & $38(54.29 \%)$ & & 1.02 & $0.59-1.75$ \\
\hline \multicolumn{6}{|l|}{ SRE at diagnosis } \\
\hline No & 818 & $368(45.0 \%)$ & \multirow{2}{*}{$<.001$} & Ref & Ref \\
\hline Yes & 491 & $352(71.7 \%)$ & & 2.60 & $1.98-3.40$ \\
\hline
\end{tabular}

Abbreviations: AOR, adjusted odds ratio; IMiD, immunomodulatory imide agent; N/A, not applicable; PI, proteasome inhibitor; SES, socioeconomic status; SRE, skeletal-related event.

atatistically significant results are in bold.

${ }^{b}$ Asian, Hispanic, Native American, and unknown

'Other cytotoxic agents \pm steroids $(n=34) ; I M i D+$ other cytotoxic agents \pm steroids $(n=10)$; and PI + IMiD + other cytotoxic agents \pm steroids $(n=26)$

rate ratio, $0.58 ; P<.001$ ) and lower rates of SREs (incidence rate ratio, $0.63 ; P<.001$ ). These benefits were most prolonged in patients who used zoledronic acid the longest. ${ }^{26}$ In comparison to this study, we examined a more uniform population (newly diagnosed, treated patients) in which everyone should receive a bisphosphonate, and incorporated more demographic and clinical variables.

Median time to initiation of bisphosphonates in our cohort was 52 days after the start of antineoplastic therapy. One potential explanation for the delay is the time associated with obtaining a baseline dental examination, which is recommended before bisphosphonate use.,27 Because we only had data on bisphosphonate use from 2012 through 2013, we were not able to meaningfully ex- amine duration of use. Most guidelines recommend use for at least 2 years, ${ }^{2-4}$ although the optimal duration has not been clearly established. ${ }^{28}$ We did find that, on average, patients received 2 doses of bisphosphonates every 3 months, which is lower than the monthly dosing currently recommended by guidelines for patients with active MM on antineoplastic therapy. ${ }^{2-4}$ However, evidence now suggests that one dose of zoledronic acid every 3 months is noninferior to monthly dosing for the prevention of SREs, ${ }^{29}$ suggesting that some patients may have received adequate preventive therapy for bone disease.

Our findings that bisphosphonate use decreased in patients with chronic kidney disease and hemodialysis and increased in patients with an SRE at diagnosis and hypercalce- 


\begin{tabular}{|c|c|c|}
\hline Parameter & $\begin{array}{c}\text { HR } \\
\text { (for Death) }^{\mathrm{a}}\end{array}$ & $95 \% \mathrm{Cl}^{\mathrm{a}}$ \\
\hline \multicolumn{3}{|l|}{ Bisphosphonate use } \\
\hline Users vs nonusers & 0.70 & $0.56-0.88$ \\
\hline \multicolumn{3}{|l|}{ Age group, y } \\
\hline $75-84$ vs $65-74$ & 1.25 & $1.00-1.58$ \\
\hline$\geq 85$ vs $65-74$ & 1.98 & $1.37-2.87$ \\
\hline \multicolumn{3}{|l|}{ Sex } \\
\hline Female vs male & 0.76 & $0.59-0.97$ \\
\hline \multicolumn{3}{|l|}{ Race } \\
\hline Black vs white & 0.99 & $0.72-1.35$ \\
\hline Other ${ }^{b}$ vs white & 1.07 & $0.69-1.65$ \\
\hline \multicolumn{3}{|l|}{ Marital status } \\
\hline Married vs unmarried & 1.09 & $0.86-1.37$ \\
\hline \multicolumn{3}{|l|}{ Region } \\
\hline North Central vs North East & 1.03 & $0.68-1.56$ \\
\hline South vs North East & 1.23 & $0.86-1.76$ \\
\hline West vs North East & 1.05 & $0.76-1.47$ \\
\hline \multicolumn{3}{|l|}{ SES rank, quintile } \\
\hline Second vs lowest & 0.98 & $0.72-1.32$ \\
\hline Third vs lowest & 0.97 & $0.70-1.34$ \\
\hline Fourth vs lowest & 0.95 & $0.66-1.37$ \\
\hline Highest vs lowest & 0.85 & $0.58-1.26$ \\
\hline \multicolumn{3}{|l|}{ Acute kidney injury } \\
\hline Yes vs no & 1.16 & $0.88-1.53$ \\
\hline \multicolumn{3}{|l|}{ Chronic kidney disease } \\
\hline Yes vs no & 1.01 & $0.77-1.33$ \\
\hline \multicolumn{3}{|l|}{ Osteoporosis } \\
\hline Yes vs no & 1.21 & $0.94-1.54$ \\
\hline \multicolumn{3}{|l|}{ Osteopenia } \\
\hline Yes vs no & 1.02 & $0.82-1.28$ \\
\hline \multicolumn{3}{|l|}{ Hypercalcemia } \\
\hline Yes vs no & 1.37 & $1.06-1.78$ \\
\hline \multicolumn{3}{|l|}{ Hemodialysis } \\
\hline Yes vs no & 1.50 & $1.01-2.22$ \\
\hline \multicolumn{3}{|l|}{ Comorbidity score } \\
\hline 1 vs 0 & 0.85 & $0.63-1.16$ \\
\hline$\geq 2$ vs 0 & 1.32 & $1.01-1.72$ \\
\hline \multicolumn{3}{|l|}{ Antineoplastic regimen } \\
\hline $\mathrm{IMiD} \pm$ steroid vs $\mathrm{PI} \pm$ steroid & 0.77 & $0.56-1.07$ \\
\hline $\mathrm{PI}+\mathrm{IMiD} \pm$ steroid vs $\mathrm{PI} \pm$ steroid & 0.67 & $0.48-0.92$ \\
\hline $\begin{array}{l}\mathrm{Pl}+\text { other cytotoxic } \pm \text { steroid vs } \mathrm{PI} \pm \\
\text { steroid }\end{array}$ & 0.97 & $0.71-1.31$ \\
\hline Other vs $\mathrm{PI} \pm$ steroid & 0.79 & $0.49-1.29$ \\
\hline \multicolumn{3}{|l|}{ SRE at diagnosis } \\
\hline Yes vs no & 1.23 & $0.97-1.57$ \\
\hline
\end{tabular}

Abbreviations: $\mathrm{HR}$, hazard ratio; IMiD, immunomodulatory imide agent; $\mathrm{PI}$, proteasome inhibitor; SES, socioeconomic status; SRE, skeletal-related event.

aStatistically significant results in bold.

${ }^{b}$ Asian, Hispanic, Native American, and unknown. mia conform to clinical practice and thus is not surprising. We also found that patients who received proteasome inhibitor + IMiD \pm steroid ("triplet") regimens had increased use of bisphosphonates, which supports the notion that those who receive the most up-to-date antineoplastic therapies are also more likely to receive other guideline-based care. Interestingly, these patients also had improved survival compared with those receiving proteasome inhibitors without IMiDs, but we could not tell whether this effect is from increased use of up-to-date and guideline-based care or from differences in disease or patient characteristics. The finding that bisphosphonate use impacted survival is biologically plausible and is in accordance with results of some prospective studies. ${ }^{8,10}$ Bisphosphonates induce osteoclast apoptosis through inhibiting the mevalonate pathway required for the prenylation of proteins such as Ras, ${ }^{30}$ helping to restore bone health. They have antiproliferative effects against MM cells, and also antiangiogenic and immunomodulatory properties. ${ }^{31,32}$

Strengths of our study include the use of a nationally representative database and examination of bisphosphonates users compared with nonusers. Our study also has important limitations. Our population only included patients aged $\geq 65$ years and reflected $<10 \%$ of those with newly diagnosed MM in the United States during the period included. We lacked data on dental health, an important mediator of bisphosphonate use. We also lacked other important covariates that could predict outcomes, such as disease stage, cytogenetics, or response to therapy, although none of these variables should affect the decision to treat patients with bisphosphonates. Use of billing codes to capture data can lead to undercapture of interventions. Our data covered only 2012 through 2013, because more recent data had not yet been released at study initiation; nonetheless, this limited our ability to examine bisphosphonate use over a longer interval.

\section{Conclusions}

We found that $55 \%$ of patients with newly diagnosed MM who received antineoplastic therapy were given a bisphosphonate in accordance with national guidelines. Given the clinical evidence supporting the effectiveness of bisphosphonates in MM, we advocate for efforts to increase bisphosphonate use in these patients.

\footnotetext{
Submitted June 29, 2018; accepted for publication August 20, 2018.
}

Disclosures: Dr. Lentzsch has disclosed that she has served on the advisory board for Bristol-Myers Squibb, Bayer, Janssen, Proclara Biosciences, and Takeda. The remaining authors have disclosed that they have not received any financial considerations from any person or organization to support the preparation, analysis, results, or discussion of this article.

Funding: This work was supported by the $\mathrm{NCl}$ under grants R25 CA094061 (Leng), R01 CA166084 (Hershman), and R01 CA169121 (Wright).

Correspondence: Siyang Leng, MD, MS, Department of Medicine, Columbia University Medical Center, 161 Fort Washington Avenue, Garden Level G, New York, NY 10032. Email: SL4076@cumc.columbia.edu 


\section{References}

1. Kyle RA, Gertz MA, Witzig TE, et al. Review of 1027 patients with newly diagnosed multiple myeloma. Mayo Clin Proc 2003;78:21-33.

2. Terpos E, Morgan G, Dimopoulos MA, et al. International Myeloma Working Group recommendations for the treatment of multiple myeloma-related bone disease. J Clin Oncol 2013:31:2347-2357.

3. Terpos E, Kleber M, Engelhardt M, et al. European Myeloma Network guidelines for the management of multiple myeloma-related complications. Haematologica 2015;100:1254-1266.

4. Anderson K, Ismaila N, Flynn PJ, et al. Role of bone-modifying agents in multiple myeloma: American Society of Clinical Oncology clinical practice guideline update. J Clin Oncol 2018;36:812-818.

5. Kumar SK, Callander NS, Biermann JS, et al. NCCN Clinical Practice Guidelines in Oncology: Multiple Myeloma. Version 2.2019. Accessed December 2, 2018. To view the most recent version of these guidelines, visit NCCN.org.

6. Berenson JR, Lichtenstein A, Porter L, et al. Efficacy of pamidronate in reducing skeletal events in patients with advanced multiple myeloma. Myeloma Aredia Study Group. N Engl J Med 1996;334:488-493.

7. Rosen LS, Gordon D, Kaminski M, et al. Long-term efficacy and safety of zoledronic acid compared with pamidronate disodium in the treatment of skeletal complications in patients with advanced multiple myeloma or breast carcinoma: a randomized, double-blind, multicenter, comparative trial. Cancer 2003:98:1735-1744.

8. Berenson JR, Lichtenstein A, Porter L, et al. Long-term pamidronate treatment of advanced multiple myeloma patients reduces skeletal events. Myeloma Aredia Study Group. J Clin Oncol 1998;16:593-602.

9. Mhaskar R, Redzepovic J, Wheatley K, et al. Bisphosphonates in multiple myeloma: a network meta-analysis. Cochrane Database Syst Rev 2012:CD003188.

10. Morgan GJ, Davies FE, Gregory WM, et al. First-line treatment with zoledronic acid as compared with clodronic acid in multiple myeloma (MRC Myeloma IX): a randomised controlled trial. Lancet 2010;376:1989-1999.

11. Morgan GJ, Davies FE, Gregory WM, et al. Effects of induction and maintenance plus long-term bisphosphonates on bone disease in patients with multiple myeloma: the Medical Research Council Myeloma IX trial. Blood 2012;119:5374-5383.

12. Anderson KC, Alsina M, Bensinger W, et al. NCCN Clinical Practice Guidelines in Oncology: Multiple Myeloma. Version 1.2011. To view the most recent version of these guidelines, visit NCCN.org.

13. Wright JD, Burke WM, Tergas Al, et al. Comparative effectiveness of minimally invasive hysterectomy for endometrial cancer. J Clin Oncol 2016;34:1087-1096.

14. National Cancer Institute: Surveillance, Epidemiology, and End Results Program. About the SEER Registries. Available at: https://seer.cancer. gov/registries/. Accessed December 2, 2018.

15. Warren JL, Klabunde CN, Schrag D, et al. Overview of the SEER-Medicare data: content, research applications, and generalizability to the United States elderly population. Med Care 2002;40:IV-3-18.

16. Du XL, Fang S, Vernon SW, et al. Racial disparities and socioeconomic status in association with survival in a large population-based cohort of elderly patients with colon cancer. Cancer 2007;110:660-669.

17. Sanfilippo KM, Gage B, Luo S, et al. Comparative effectiveness on survival of zoledronic acid versus pamidronate in multiple myeloma. Leuk Lymphoma 2015;56:615-621.

18. McDougall JA, Bansal A, Goulart BH, et al. The clinical and economic impacts of skeletal-related events among medicare enrollees with prostate cancer metastatic to bone. Oncologist 2016;21:320-326.

19. Hussain A, Aly A, Daniel Mullins C, et al. Risk of skeletal related events among elderly prostate cancer patients by site of metastasis at diagnosis. Cancer Med 2016;5:3300-3309.

20. Aly A, Onukwugha E, Woods C, et al. Measurement of skeletal related events in SEER-Medicare: a comparison of claims-based methods. BMC Med Res Methodol 2015;15:65.

21. Klabunde CN, Potosky AL, Legler JM, et al. Development of a comorbidity index using physician claims data. J Clin Epidemio 2000;53:1258-1267.

22. Cox DR. Regression models and life-tables. J R Stat Soc Series B Stat Methodol 1972;34:187-220.

23. Bloomfield DJ. Should bisphosphonates be part of the standard therapy of patients with multiple myeloma or bone metastases from other cancers? An evidence-based review. J Clin Oncol 1998;16:1218-1225.

24. Berenson JR, Hillner BE, Kyle RA, et al. American Society of Clinical Oncology clinical practice guidelines: the role of bisphosphonates in multiple myeloma. J Clin Oncol 2002;20:3719-3736.

25. Kim C, Hernandez RK, Cyprien L, et al. Patterns of bisphosphonate treatment among patients with multiple myeloma treated at oncology clinics across the USA: observations from real-world data. Support Care Cancer 2018;26:2833-2841.

26. Henk HJ, Teitelbaum A, Perez JR, et al. Persistency with zoledronic acid is associated with clinical benefit in patients with multiple myeloma. Am J Hematol 2012;87:490-495.

27. Terpos E, Roodman GD, Dimopoulos MA. Optimal use of bisphosphonates in patients with multiple myeloma. Blood 2013;121:3325-3328.

28. Raje N, Vescio R, Montgomery CW, et al. Bone marker-directed dosing of zoledronic acid for the prevention of skeletal complications in patients with multiple myeloma: results of the Z-MARK study. Clin Cancer Res 2016;22:1378-1384.

29. Himelstein AL, Foster JC, Khatcheressian JL, et al. Effect of longer-interval vs standard dosing of zoledronic acid on skeletal events in patients with bone metastases: a randomized clinical trial. JAMA 2017;317:48-58.

30. Luckman SP, Hughes DE, Coxon FP, et al. Nitrogen-containing bisphosphonates inhibit the mevalonate pathway and prevent post-translational prenylation of GTP-binding proteins, including Ras. J Bone Miner Res 1998;13:581-589.

31. Corso A, Ferretti E, Lazzarino M. Zoledronic acid exerts its antitumor effect in multiple myeloma interfering with the bone marrow microenvironment. Hematology 2005;10:215-224.

32. Modi ND, Lentzsch S. Bisphosphonates as antimyeloma drugs. Leukemia 2011:26:589-594

\section{See JNCCN.org for supplemental online content.}

